\title{
Design of “Iris", a Small Autonomous Surveillance UAV
}

\author{
Jennifer Boyce ${ }^{1}$, Ryan Carr $^{1}$, Donovan Chipman ${ }^{1}$, Doug Hunsaker ${ }^{1}$, Greg Larson ${ }^{1}$, Nathan Hopkins ${ }^{1}$, \\ and Dr. W. Jerry Bowman ${ }^{2}$ \\ Brigham Young University, Provo Utah 84602
}

This paper documents the design process used for a small autonomous surveillance UAV. The most significant requirements for the plane were size (man-packable), endurance (about 1 hour) and cost (essentially disposable). The plane that resulted, named "Iris", is a tailless plane with a $45 \mathrm{~cm}$ wing span and a total mass of less than 200g. During flight tests, it achieved an endurance of 52 minutes. The estimated cost to manufacture the planes was $\$ 343$, excluding the autopilot.

\section{Nomenclature}

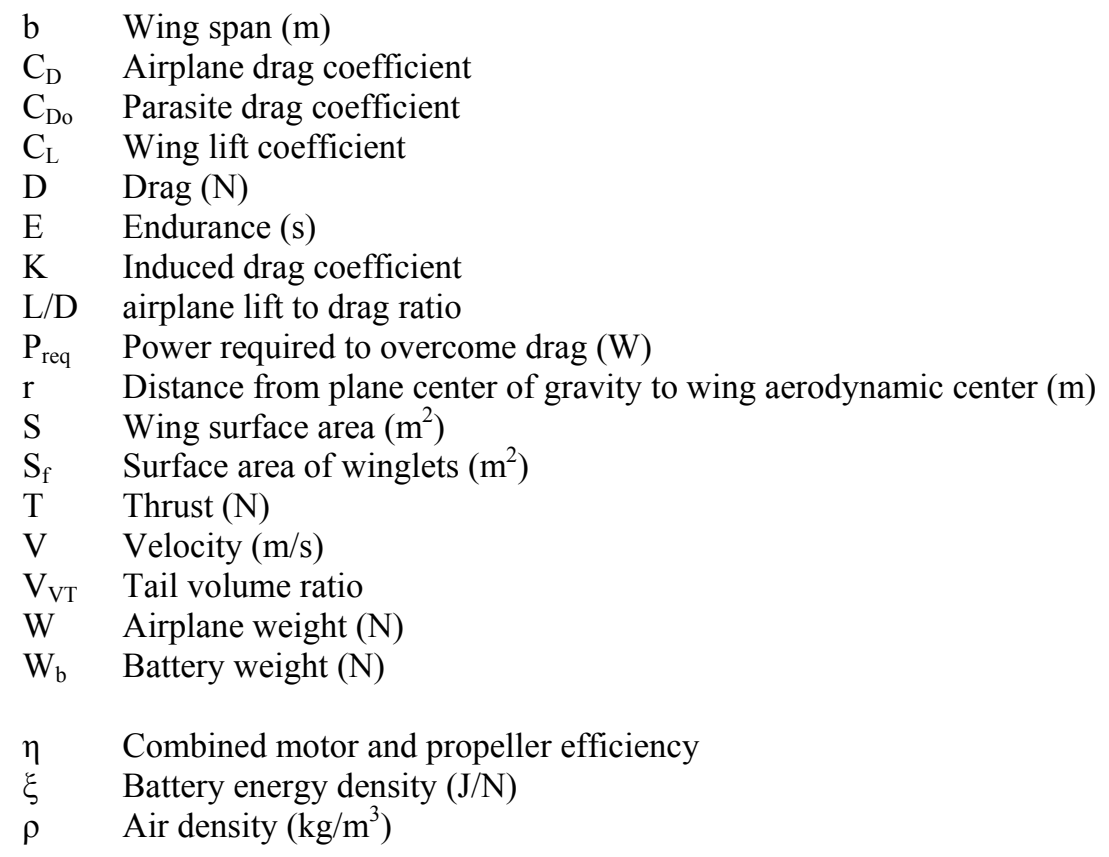

\section{Introduction}

NE exciting technology being developed in the aircraft industry is the ability to remove the pilot from the cockpit, making the aircraft fully autonomous. Airplanes that make use of this technology are called Unmanned Air Vehicles, or UAV's. As UAV technology develops, components used for autonomous control decrease in size and weight. This makes the development of small UAV's (SUAV) possible. SUAV's find numerous applications for reconnaissance purposes with military, border patrol, search and rescue, pipeline monitoring, and traffic reporting. Companies including Northrop Grumman, Boeing, and AeroVironment are among the major developers of SUAV's currently used for military purposes. Fully autonomous UAVs now on the market range in size from the Raven (by AeroVironment) which has about a 6' wingspan to the Predator (by

\footnotetext{
${ }^{1}$ Mechanical Engineering Student, Mechanical Engineering, 435 CTB, AIAA Student Member.

${ }^{2}$ Associate Professor, Mechanical Engineering, 435 CTB, AIAA Senior Member.
} 
Northrop Grumman) which has a 116' wingspan. Recently, a need has arisen for a less expensive, more portable SUAV. This SUAV should be easily carried by a single person, launched by hand with minimal assembly, and be used for flights of up to one hour endurance.

The key functional specifications for the aircraft are as follows:

- Wing span under $60 \mathrm{~cm}$

- Endurance of 1+ hours

- Minimal assembly (no separate parts or tools needed)

- Man-packable (breaks down or is small enough to be carried in a back pack)

- Hand launchable

- Able to fly in $25 \mathrm{mph}(12 \mathrm{~m} / \mathrm{s})$ winds

- Production cost below $\$ 500$ dollars (less autopilot)

The purpose of this paper is to provide documentation on the development of the final design and describe how each of the functional specifications was met. Documentation will proceed according to four functional subgroups: Aerodynamics, Components, Propulsion, and Structures and Manufacturing. Each section will contain associated design decisions and metric values associated with these decisions. Following the main body of the report, a short section entitled Prototype Progression will outline the lessons learned from each of the 9 prototypes that were built and flown.

\section{Design Description}

A photograph of the final design is shown in Fig. 1. A clear coating was applied to the airplane to allow visualization of the components. This plane had an endurance of just less than one hour, a wingspan of $45 \mathrm{~cm}$, and weighed only 193 grams. It can carry the Kestrel 2.0 autopilot with accompanying components as well as a small color video camera for reconnaissance.

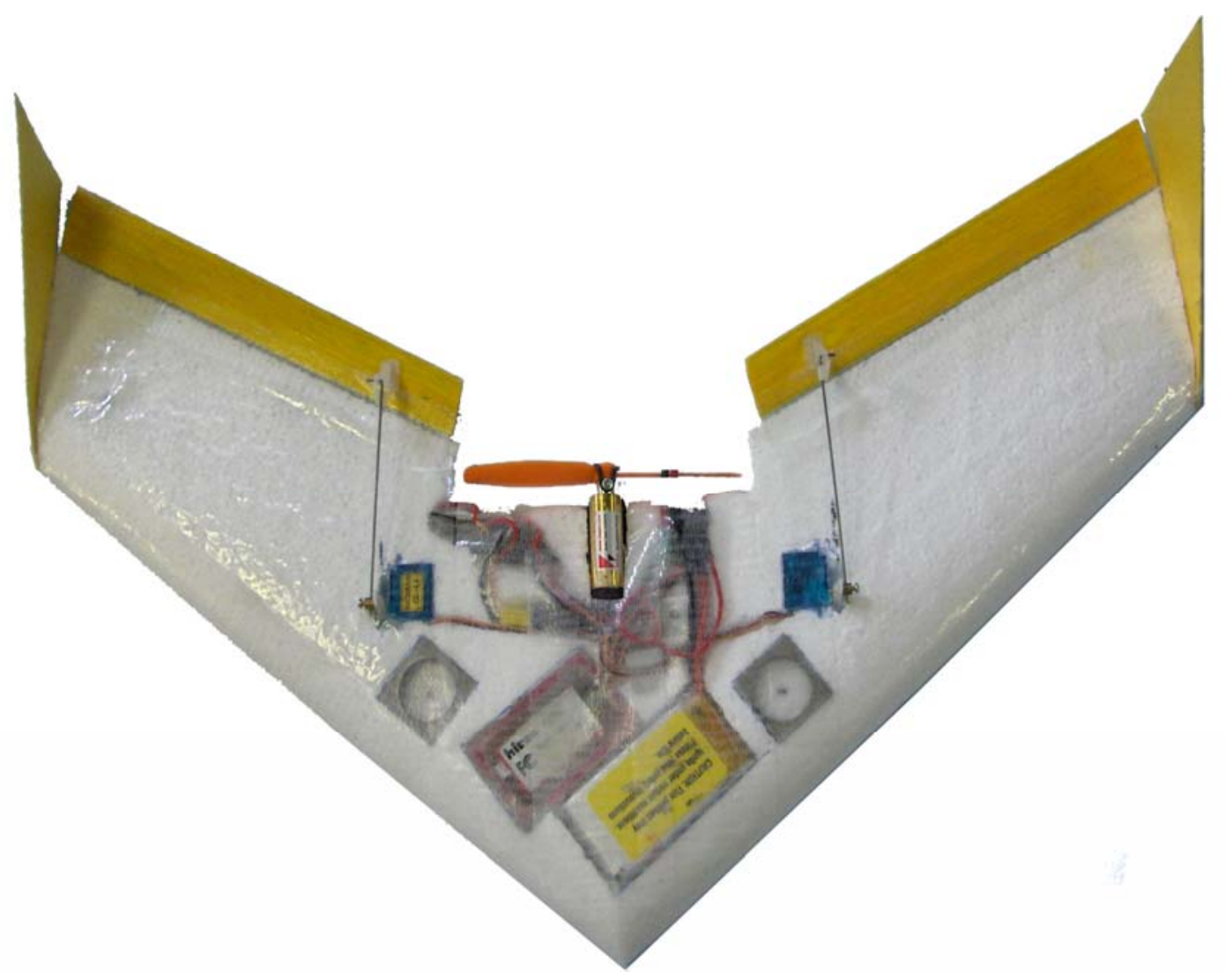

Figure 1 Photograph of the final airplane with components exposed 
The proposed design solution includes the following parameters:

- Airfoil: Chipman_Larson

- Quarter Chord Sweep: $30^{\circ}$

- Dihedral: $3^{\circ}$

- Root Chord: $15 \mathrm{~cm}$

- Tip Chord: $12.5 \mathrm{~cm}$

- Elevon Chord: $2.5 \mathrm{~cm}$

- Washout: 2 Degrees

- Center of Gravity Location (measured from leading point of airplane): $10.5 \mathrm{~cm}$

- Winglets: Triangle shape with areas of $23 \mathrm{~cm}^{2}$ each

- Wing Planform Area: $0.065 \mathrm{~m}^{2}$

- Aspect Ratio: 3.33

- Motor: Feigao 1208436L Motor

- Propeller: GWS 404 Propeller modified to a 4" x 3" propeller

- Speed Control: Phoenix 10

- Receiver: GWS Pico 5 channel

- Servos: Two Bluebird 303, 3.5 gram servos

- Battery: Thunder Power 1320 mAh 2-cell Lithium-Polymer Battery

- 50 gram dummy weight to simulate autopilot and payload

\section{A. Aerodynamics}

\section{Initial Design}

The first step in the plane design was to determine the aircraft configuration. For this project, a tailless swept wing airplane (often known as a flying wing) was chosen because it can be carried without the need to break down any structure. The flying wing design satisfies three critical functional specifications: it requires minimal assembly, it is easy to transport, and it can be set up (from case to flight) very quickly. In order to meet target values, a span of $45 \mathrm{~cm}$ was chosen, with a root chord of $15 \mathrm{~cm}$ and a tip chord of $12.5 \mathrm{~cm}$. The surface area, weight, and lift coefficient, $\left(\mathrm{C}_{\mathrm{L}}\right)$, determine the expected speed of the plane. It must be possible to hand launch the plane at its minimum velocity. (Experience shows that it is not generally possible to launch a small airplane by hand at more than $13 \mathrm{~m} / \mathrm{s}$ ). According to Eq. 1:

$$
\mathrm{V}^{2}=\frac{2 \mathrm{~W}}{\rho \mathrm{SC}_{\mathrm{L}}},
$$

where $\mathrm{W}$ is the weight of the plane, $\rho$ is the air density, and $\mathrm{S}$ is the wing surface area. The minimum velocity expected for the plane was $11 \mathrm{~m} / \mathrm{s}$.

\section{Airfoil}

An airfoil was developed to meet the particular needs of a tailless aircraft. For a flying wing configuration, it is important to have a positive moment about the wing aerodynamic center. In order to develop an airfoil with sufficient positive moment, the computer program "Xfoil" was used. "Xfoil" is free to download and can be found at http://raphael.mit.edu/xfoil. As inputs it takes data points for the airfoil, a Reynolds number, and an angle of attack. The program returns the airfoil lift coefficient, drag coefficient, lift to drag ratio, and moment coefficient along with the pressure variation over the airfoil.

Research was conducted on 400 different airfoils. Each of these airfoils was tested separately through the following process:

1. The airfoil coordinates were loaded into Xfoil.

2. The anticipated Reynolds number was entered (for cruise velocity $R e=120,000$ ).

3. The airfoil was then analyzed at angles of attack from 0 to $10^{\circ}$.

4. The resultant coefficients for lift, drag, and moment were noted. If the pitching moment was more negative than -0.02 , the airfoil was eliminated. 
Only 20 airfoils returned pitching moments greater than -0.02 . Of these 20 the airfoil with the highest lift to drag ratio, the Eppler 520, was chosen. This was used for the first three prototypes. Because prototype planes built using the Eppler 520 performed poorly, it was suspected that the airfoil was experiencing flow separation due to the low Reynolds number effects. Further analysis using Xfoil confirmed this and more airfoils were researched. Two airfoils specifically designed for flying wings at low velocities, the S6071 and the S6079, were analyzed and tested on planes. The S6071 had a higher lift to drag ratio (L/D), but had a negative moment coefficient. Both airfoils were tested on planes, with comparable performance. A new airfoil, called ChipmanLarson, was also developed using Xfoil in an attempt to improve upon these airfoils. The new airfoil had a positive moment coefficient (0.02) as well as a high L/D (47 at 10 degrees angle of attack) at the low Reynolds number the plane would be flying at. It was decided that the Chipman-Larson would be used on the final plane because this positive moment coefficient would decrease the amount of elevon deflection required to maintain stable flight.

\section{Winglets}

Winglets provide yaw stabilizing moments. Winglets were sized using the tail volume ratio defined as:

$$
\mathrm{V}_{\mathrm{VT}}=\frac{2 \mathrm{~S}_{\mathrm{f}} \mathrm{r}}{\mathrm{Sb}},
$$

where $S_{\mathrm{f}}$ is the surface area of the winglets, $\mathrm{r}$ is the distance from the center of gravity of the plane to the aerodynamic center of the winglet, and $\mathrm{b}$ is the wing span. Nickel and Wolfhart ${ }^{1}$, suggest that the tail volume ratio should range from 0.03 to 0.05 . For this design, 0.04 was used. For a triangular shaped winglet, this gives the result that each winglet, attached at the $10 \mathrm{~cm}$ tip of the wing (the wing tip chord was $12.5 \mathrm{~cm}$, of which 2.5 $\mathrm{cm}$ was the elevon), should be $4 \mathrm{~cm}$ tall.

\section{Elevons}

Elevon sizing affects the airplane's pitch and roll rates. The greatest pitching moment occurs at an elevon chord ratio of about 0.2 (elevon chord divided by wing chord). With this ratio, and the knowledge that the greatest roll moment is provided by the elevons further from the root chord, a geometry was chosen for the elevons of $2.5 \mathrm{~cm}$ near the wing tips to $2 \mathrm{~cm}$ near the wing root section.

\section{B. Components}

The choice of components was largely determined by weight. In order to fly within the prescribed velocity envelope, the total weight of the aircraft was limited to no more than 250 grams. In order to achieve this, the lightest components that still accomplished the mission were used. A listing of the chosen components and their masses is given in Table 1.

Table 1 Components and masses

\begin{tabular}{|c|c|c|}
\hline Component & Name & Mass (g) \\
\hline Autopilot & Kestrel 2.1 & 16.7 \\
\hline Modem & Aerocom 4490-100 1x1 & 9 \\
\hline GPS Antenna & Commlinx Solutions Patch & 3.3 \\
\hline Camera & Micro Color CMOS & 3 \\
\hline Transmitter & Spy Stuff SDX-22 & 3.4 \\
\hline Servos & Bluebird 303 & 17 \\
\hline Motor & Feigao Brushless & 6 \\
\hline Speed Control & Phoeniz-10 & 62 \\
\hline Batteries & Thunder Power & \\
\hline
\end{tabular}


The total mass of the non-propulsive components found in Table 1 is 54 grams. These components were intended to provide the plane with full autonomous capabilities at a range of up to 1 mile. Because it was not included in the scope of this project (largely due to funding) to actually perform fully autonomous flights, the physical components were not installed in the airframe. However, in order to demonstrate the plane's ability to house these components, dummy components of appropriate size and mass were created and were carried by the final prototype as shown in Fig. 2. All prototypes were flown using radio control only.

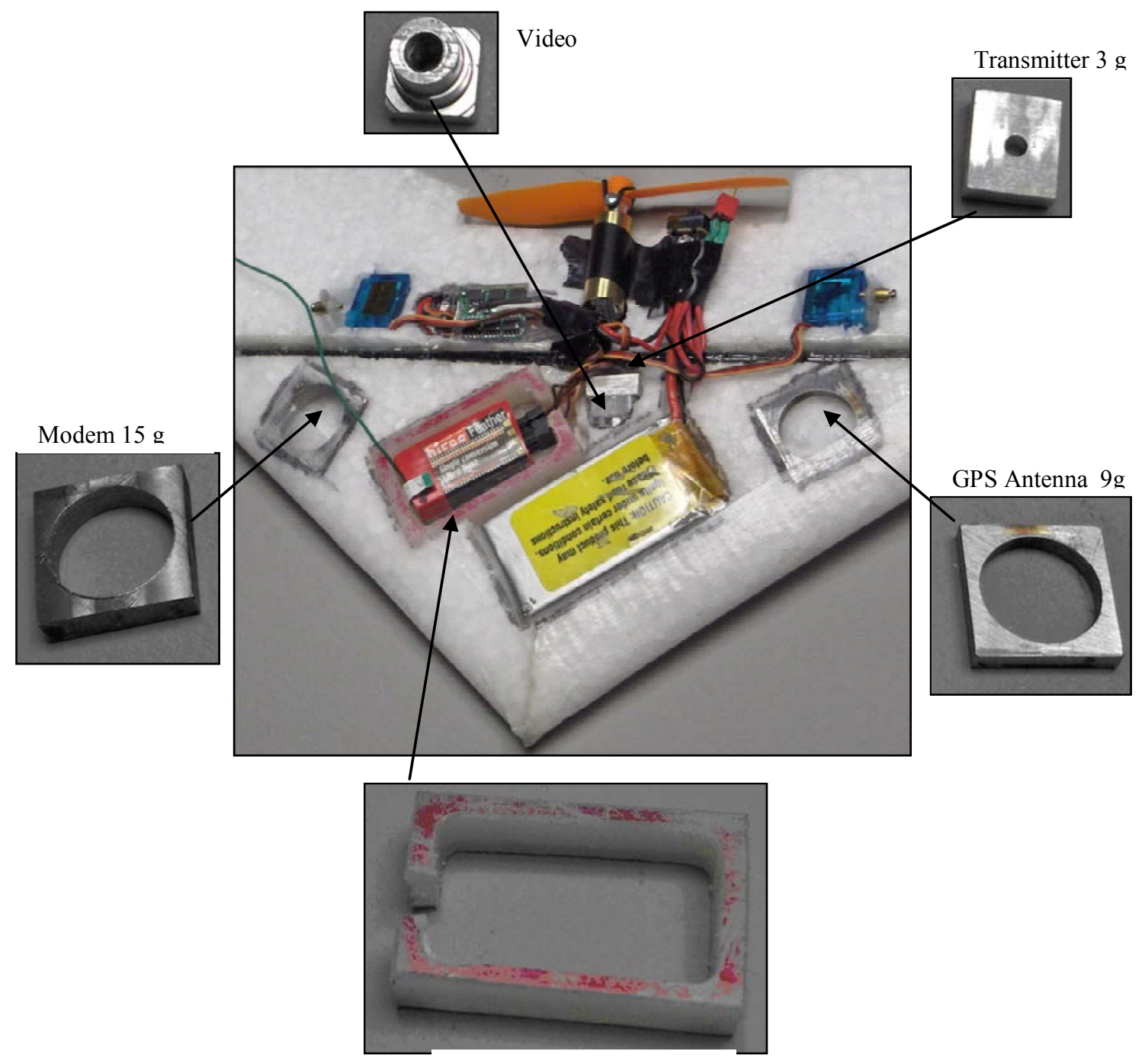

Kestrel 2.0 Autopilot 6.65

Figure 2 Autonomous simulation components and masses

Because material must be removed from the body of the plane to make space for each component, their placement affects not only the center of gravity but the structure of the entire plane. In order to make the plane strong enough, a carbon spar was added to the plane. The final placement of components is shown in Fig. 2. At the end of the development, the structure had noticeable weak points. More work needs to be done in the future to eliminate these points of potential structure failure. 


\section{Propulsion}

\section{Method of Propulsion}

Endurance is affected by many factors. These include aerodynamic factors such as airfoil characteristics (Lift to Drag ratio), and propulsive efficiency. Propulsion design decisions will now be described.

It was decided early on that propulsion for the Iris plane would be provided by a battery, an electric motor, and a propeller. This decision was made due to the high efficiency, simplicity, and reliability of an electric system at the small sizes and weights that were needed. Each propulsive component was carefully chosen to best meet the mission requirements of one hour endurance, and $\mathrm{V}_{\min }$ and $\mathrm{V}_{\max }$ of 10 and $20 \mathrm{~m} / \mathrm{s}$, respectively.

\section{Battery}

In order to select the best battery, specific energies $(\mathrm{kJ} / \mathrm{N})$ were compared for many batteries. Three popular battery types were specifically compared: Nickel Cadmium, Lithium Polymer, and Zinc Air. Specific energy values for these three battery types are listed in Table 2.

Table 2 Battery type and specific energy

\begin{tabular}{|c|c|}
\hline Battery & Specific Energy (kJ/N) \\
\hline Zinc air & 128 \\
\hline Li Poly & 48 \\
\hline NiCad & 20 \\
\hline
\end{tabular}

As can be seen, the specific energy of Zinc Air exceeds the other two. However, Zinc Air batteries are expensive and cannot be recharged. It was felt that although rechargeability is not specifically a mission requirement, it is a necessity for the prototyping of the plane. For this reason, Lithium Polymer batteries were chosen for the plane. However, it is recommended that as Zinc Air batteries, be considered as an option to improve endurance of the airplane.

Now that the battery type had been selected, it was necessary to predict the battery capacity required for a one hour flight. Battery weight fraction can be found from the equation:

$$
\frac{\mathrm{W}_{\mathrm{b}}}{\mathrm{W}}=\frac{\mathrm{VE}}{\xi(\mathrm{L} / \mathrm{D}) \mathrm{\eta}}
$$

where $\mathrm{W}_{\mathrm{b}} / \mathrm{W}$ is the battery weight fraction, $\mathrm{E}$ is the plane endurance, $\xi$ is the battery energy density $(\mathrm{J} / \mathrm{N})$, and $\eta$ is the combined efficiency of the motor, propeller and electronics. It was found that the battery to total plane weight percentage would be no greater than $25 \%$. Since the total plane was constrained to 250 grams, this limited the battery to about 60 grams. It was found that the maximum capacity available within that weight limit was a ThunderPower 2-cell, $1320 \mathrm{mAh}$ battery which has a mass of $62 \mathrm{~g}$.

\section{Motor}

As mentioned previously, the motor needed to provide sufficient power to enable the plane to achieve a maximum velocity of $20 \mathrm{~m} / \mathrm{s}$. An analysis was performed on the plane to find the amount of power that would be needed. The coefficient of drag, $\mathrm{C}_{\mathrm{D}}$, is:

$$
\mathrm{C}_{\mathrm{D}}=\mathrm{C}_{\mathrm{Do}}+\mathrm{KC}_{\mathrm{L}}^{2}
$$

where $\mathrm{C}_{\mathrm{Do}}$ is the parasite drag coefficient and $\mathrm{K}$ is the induced drag coefficient. $\mathrm{K}$ is found from the wing aspect ratio and the Oswald Efficiency factor (e). The coefficient of drag is used to find the drag on the plane, or thrust from the motor using Eq. 5:

$$
\mathrm{D}=\frac{1}{2} \mathrm{C}_{\mathrm{D}} \rho \mathrm{SV} \mathrm{V}^{2}=\mathrm{T}
$$

Thrust is used to find the required power using Eq. 6: 


$$
\mathrm{T} \times \mathrm{V}=\mathrm{P}_{\text {req }} .
$$

$\mathrm{P}_{\text {req }}$ is the power required from the propeller to overcome drag. A flight velocity vs. required power curve was generated. This plot is seen in Fig. 3. At cruise velocity, $15 \mathrm{~m} / \mathrm{s}$, power required is $5.1 \mathrm{~W}$, and at max velocity, $20 \mathrm{~m} / \mathrm{s}$, power required is $11.6 \mathrm{~W}$.

It was then necessary to decide which motor could supply the power required. The power rating of a motor is typically the shaft power of the motor. This is related to the power available from propulsion by the propeller efficiency. Assuming a propeller efficiency of $70 \%$, the shaft power required at maximum velocity would be 15 W. Many motors were analyzed. Five of the most probable candidates based on weight $(<50$ grams $)$ and reported power are shown below. Note that the power given is not power output of the propeller, but shaft power.

Table 3 Motor Specifications

\begin{tabular}{|c|c|c|}
\hline Motor & Power (W) & Mass(g) \\
\hline Mighty Micro & 60 & 49 \\
\hline Firefly (x2) & 14 & 20 \\
\hline Medusa 4000 & 40 & 15 \\
\hline Medusa 5300 & 48 & 15 \\
\hline Feigao 1208436L & 33 & 17 \\
\hline
\end{tabular}

The Feigao was chosen for the final prototype. The Medusa motors were not selected because they were newly developed and inaccessible. In order to simplify motor and propeller efficiency analysis, pre-existing software called "Mprop" was used along with an iteration routine. Analysis was performed on the Feigao motor with many different propeller parameters.

\section{Efficiency Analysis}

Mprop takes motor, propeller, and battery parameters, along with flight conditions as input and predicts current draw and throttle setting required to produce the needed thrust at the given airspeed. Along with the throttle setting, Mprop predicts the efficiencies of the propeller, motor, and overall efficiency of the system. The program was used to analyze many different propellers until a satisfactory propeller was found. An acceptable propeller would yield a combined motor and propeller efficiency of about $50 \%$ at Vcruise $=15 \mathrm{~m} / \mathrm{s}$ and produce enough thrust to fly at Vmax $=20 \mathrm{~m} / \mathrm{s}$.

For cruise velocity, the following parameters and values were entered as inputs:

Motor specifications:

Motor voltage constant $\quad 4122 \mathrm{rpm} / \mathrm{V}$

No load motor current $\quad 0.3$ Amps

Motor armature resistance $\quad 0.585 \mathrm{Ohms}$

Motor Gear Ratio $\quad 1: 1$

Battery specifications:

Battery voltage $\quad 7.4 \mathrm{~V}$

Battery internal resistance $\quad 0.25 \mathrm{Ohms}$

Propeller specifications:

Propeller diameter Iterative

Propeller Pitch Iterative

Number of Propeller blades 2

Flight Conditions:

Air Density

Air speed

$1.23 \mathrm{~kg} / \mathrm{m}^{3}$

$15 \mathrm{~m} / \mathrm{s}$

In order to quickly analyze many different propellers, a program was written that would run Mprop iteratively, changing the propeller diameter and pitch. Output data was obtained containing the throttle setting 
and the efficiencies of the motor and propeller. The maximum system efficiency of 0.517 occurs for a propeller with a diameter of 3.5", a pitch of $1.75 "$, and at cruise velocity. However, this efficiency occurs at a $100 \%$ throttle setting. Even though the 3.5X1.75 propeller was most efficient, it was rejected because it could not achieve the maximum desired velocity. The system efficiency of a $4 \times 3$ propeller at $60 \%$ throttle was still fairly good, 0.48 , and there was still enough excess power to achieve maximum velocity. The current draw at this setting and prop combination is 2.2 Amps. Once the efficiencies were obtained, it was possible to generate a power available curve. This curve is seen in Fig. 3. It was found that the power available was sufficient to achieve a velocity of $20 \mathrm{~m} / \mathrm{s}$.

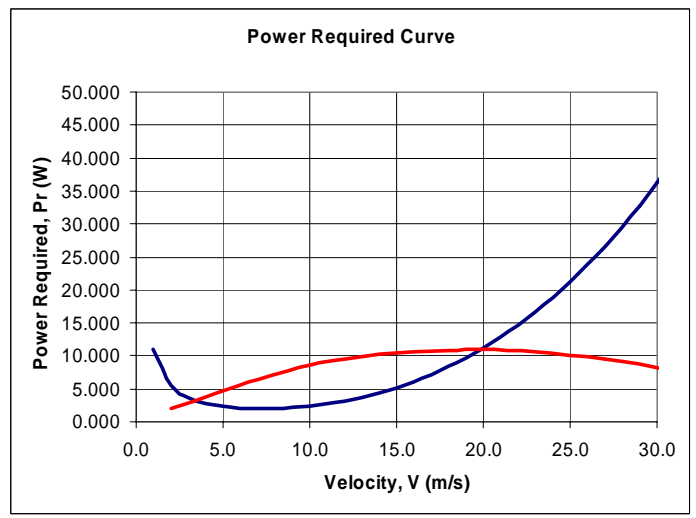

Figure 3 Power required and power available vs. velocity (darker line is power required; lighter line is power, available)

\section{Endurance}

After the combined efficiency $\left(\eta_{\mathrm{p}}{ }^{*} \eta_{\mathrm{m}}\right)$ was found, the expected endurance of the plane was calculated. This was done by defining a battery efficiency, $\eta_{b}$, defined as the ratio of the actual to expected capacities. For the $1320 \mathrm{mAh}$ Thunderpower batteries, this was found experimentally to be 0.97 . Flight endurance was calculated by Eq. 7 :

$$
\text { Endurance }=\frac{\eta_{\mathrm{p}} \eta_{\mathrm{m}} \eta_{\mathrm{b}} \times \text { Capacity } \times \text { Voltage }}{\mathrm{P}_{\text {req }}}
$$

The predicted endurance was found to be 62 minutes. Prototype 8 , which did not contain the autonomous simulation weights, achieved an endurance of 58 minutes. This value is slightly less than predicted especially considering it was a lighter model than what the design analysis had assumed. This may be due to various effects, including: wind, cold batteries, under-predicted parasite drag, power loss during turns, and overpredicted efficiency. By adjusting the overall efficiency from .48 to .45 , the prediction was changed to match with the actual value. This made it possible to accurately predict future endurance tests. The final prototype was not fully endurance tested, due to inclement weather. However, a reasonable prediction was made. With the autonomous dummy weights, the final prototype was slightly heavier than prototype 8 . This resulted in more power required, and thus a lower endurance. It was predicted that the plane would be able to fly for 50 minutes. Although a full endurance test was not possible, energy consumption was obtained for a 20 minute flight. With knowledge of the total energy available, the endurance was calculated to be 45 minutes. It can be reasonably supposed, then, that a final endurance for the Iris plane, fully loaded, is between $45-50$ minutes.

\section{Structures and Manufacturing}

A manufacturing process needed to be chosen. Using a solid foam wing was selected over a composite hollow structure due to cost. The concept selected was to produce foam wing cores with pockets ready cut for the components. Early on, several options were explored; however, three different options proved to be most cost effective and efficient, depending on the size of the production run. The three processes considered were 
expansion foam molding, steam mold outsourcing, and $\mathrm{CNC}$ wire cutting combined with $\mathrm{CNC}$ milling to cut component cavities.

\section{Cost Analysis}

Time was spent researching costs associated with facilities, machines, tooling, molds, manufacturing materials, labor, and shipping costs for two different run sizes of 1000 planes and 10,000 planes. Experts and manufacturing companies were interviewed to obtain cost values for the two run sizes. The results in cost per plane (less electronic components) for the two run sizes are shown in Table 4.

Table 4 Cost Analysis for Manufacturing (components cost not included)

\begin{tabular}{|c|c|c|}
\hline Manufacturing Process & Cost per plane for 1000 units (\$) & For 10,000 units (\$) \\
\hline Expansion foam method & 257 & 152 \\
\hline Wire cutting method & 203 & 92 \\
\hline Steam mold outsourcing & 80 & 65 \\
\hline
\end{tabular}

As can be seen, for both production runs, steam mold outsourcing proves to be the lowest cost method. This is obviously the best option. It saves more than 100 dollars per plane (over the other processes) on a run of 1000 planes because there is no machine, tooling, or facility cost associated with it. The overall cost of one plane was then calculated. Table 5 shows the costs per part of the previously established components for 1,1000 , and 10,000 units. For a run of 10,000 planes, the total cost of the components, without the autopilot, is estimated to be $\$ 343$.

Table 5 Components Cost

\begin{tabular}{|c|c|c|c|}
\hline Component & Cost per unit, 1 unit (\$) & $\begin{array}{c}\text { Cost per unit, 1000 } \\
\text { units (\$) }\end{array}$ & $\begin{array}{c}\text { Cost per unit, 10,000 } \\
\text { units (\$) }\end{array}$ \\
\hline AutoPilot & 5000 & 3025 & 2468 \\
\hline Modem & 50 & 26 & 24 \\
\hline GPS Antenna & 17 & 9 & 8 \\
\hline Video Camera & 80 & 41 & 38 \\
\hline Video Transmitter & 395 & 201 & 190 \\
\hline Servos & 17 & 9 & 8 \\
\hline Motor & 40 & 20 & 19 \\
\hline Propeller & 2 & 1 & 17 \\
\hline Speed control & 60 & 31 & 17 \\
\hline Batteries & 36 & 18 & $\mathbf{2 8 1 1}$ \\
\hline Total & $\mathbf{5 6 9 7}$ & $\mathbf{3 3 8 9}$ & \\
\hline
\end{tabular}




\section{Prototype Progression}

Nine prototypes were built to test design assumptions. All of these prototypes were radio controlled. With each prototype, lessons were learned and used to improve subsequent prototypes. Below is presented the progression of prototypes and the lessons learned for each.

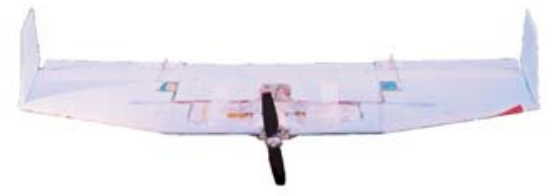

Prototype 1

-Add dihedral to improver roll stability ( $>2 \mathrm{deg}$ ) -Improve craftsmanship of winglets to reduce yaw instability (make them flat)

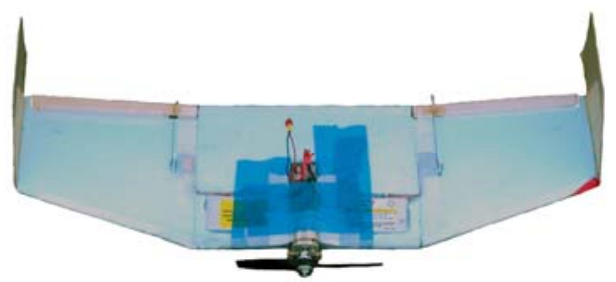

Prototype 3

-Increased washout was necessary to reduce wing tip stall (use $2^{\circ}$ )

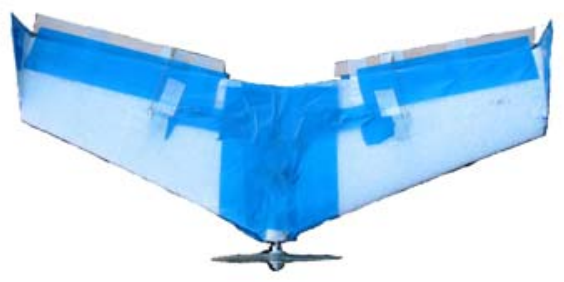

Prototype 5

-Elevons must not be in a region of flow separation -Airfoil was changed to eliminate flow separation
Prototype 2

-Validated winglet sizing method (see Winglets section of this report)

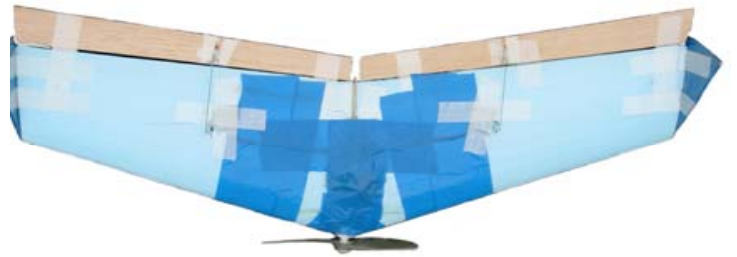

Prototype 4

-Sweep was added to the wing to allow for a more aft Center of Gravity

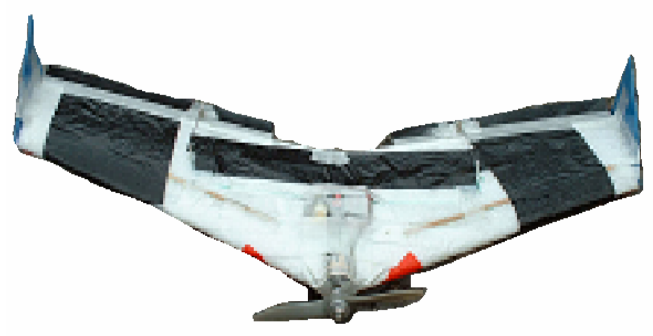

Prototype 6

-Static Margin between 3-6\% is crucial for longitudinal stability 


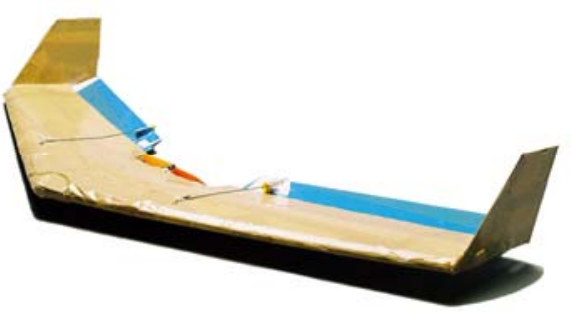

Prototype 7

-Achieved an endurance of 25 minutes

-Good pitch, roll and yaw stability

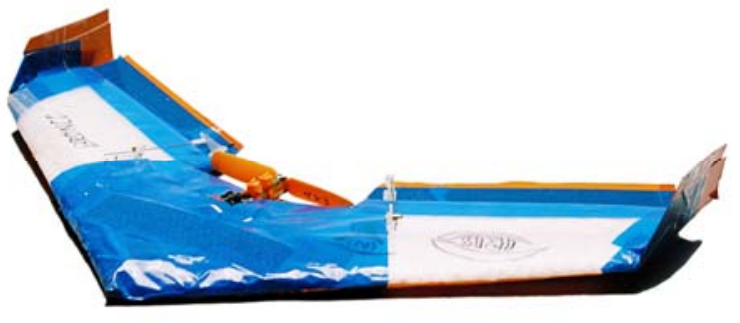

Prototype 8

-Achieved an endurance of 58 minutes without the required payload

-Good pitch, roll and yaw stability

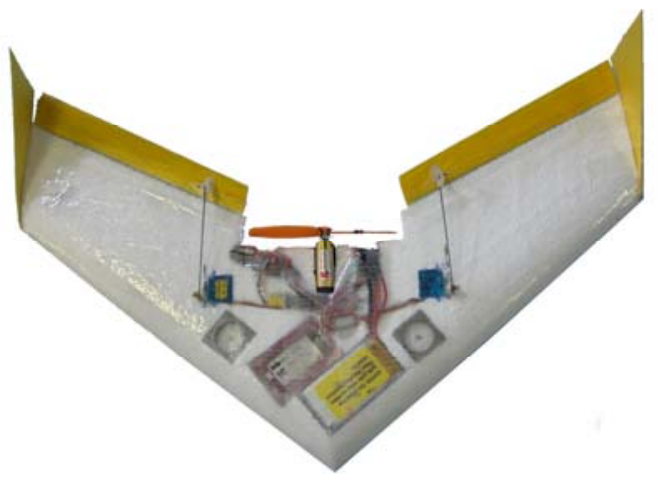

Prototype 9

-Simulated payload and autopilot included

-No full endurance flight test done due to weather

-50 minute expected endurance (extrapolation from 20 minute endurance test) 


\section{Conclusion}

The goal of this project was to produce a man-packable UAV capable of autonomous flight, while achieving flight endurance of up to one hour. This goal has been largely achieved, as can be seen in Table 7, which is a list of metrics, target values, and achieved values. The $45 \mathrm{~cm}$ wingspan allows for easy portability. Sixteen out of the 19 original target values were achieved, two have yet to be measured (\#7 - adverse wind conditions, \#18 climb rate), and the endurance of the plane is about $80 \%$ of target intended value.

Table 6 Metric versus Target and Achieved Values

\begin{tabular}{|r|l|l|r|l|r|}
\cline { 2 - 6 } \multicolumn{1}{c|}{ Metric } & \multicolumn{1}{c|}{ Units } & $\begin{array}{c}\text { Target } \\
\text { Value }\end{array}$ & \multicolumn{1}{c|}{ Acceptance Test } & $\begin{array}{c}\text { Achieved } \\
\text { Value }\end{array}$ \\
\hline 1 & Total Flight Time & Minutes & 60 & Flight-test & 50 \\
\hline 2 & Set-up (from case to flight) & Seconds & 300 & Time test & 180 \\
\hline 3 & Broken Down Max Dimension & $\mathrm{cm}$ & 60 & Measured & 45 \\
\hline 4 & Carrying Case Dimensions & $\mathrm{cm}^{3}$ & 4800 & Measured & 4680 \\
\hline 5 & Minimum Flight Velocity & $\mathrm{m} / \mathrm{s}$ & 10 & Flight-test & 11 \\
\hline 6 & Maximum Flight Velocity & $\mathrm{m} / \mathrm{s}$ & 18 & Flight-test & 20 \\
\hline 7 & Wind Speed (stability in adverse winds) & $\mathrm{m} / \mathrm{s}$ & 10 & Flight-test & YTBD* \\
\hline 8 & Payload Capacity & $\mathrm{g}$ & 50 & Measured & 50 \\
\hline 9 & Structure Cost & $\$$ & 20 & Financial Analysis & 5.5 \\
\hline 10 & Components Cost (less autopilot) & $\$$ & 100 & Financial Analysis & 343 \\
\hline 11 & Production Time & Man-hours & 2 & Financial Analysis & 1.5 \\
\hline 12 & Production Cost & $\$$ & 20 & Financial Analysis & 60 \\
\hline 13 & Total Cost (less autopilot) & $\$$ & 500 & Financial Analysis & 408 \\
\hline 14 & Range & $\mathrm{km}$ & 30 & Flight-test & 33 \\
\hline 15 & Total Weight & $\mathrm{kg}$ & 0.3 & Measured & 0.195 \\
\hline 16 & Peak Altitude & $\mathrm{m}$ & 150 & Flight-test & $150+$ \\
\hline 17 & Life Expectancy & \# Flights & 10 & Flight-test & 10 \\
\hline 18 & Climb Rate & $\mathrm{m} / \mathrm{s}$ & 2.6 & Flight-test & YTBD* \\
\hline 19 & Number of People to Operate & People & 1 & Flight-test & 1 \\
\hline
\end{tabular}

*Yet to be determined - these metrics must be measured with instruments contained in the autopilot.

\section{References:}

1. Nickel, K., and M. Wohlfahrt, Tailless Aircraft in Theory and Practice, AIAA, 1994. 